\title{
Regulating primary microplastics in the European Union
}

Christoph Rheinberger ( $\nabla$ rheinberger.cm@gmail.com )

European Chemicals Agency https://orcid.org/0000-0001-5562-6965

\section{Perrti Elo}

European Chemicals Agency

\section{Sanna Henrichson}

European Chemicals Agency

\section{Anu Kapanen}

European Chemicals Agency

\section{Sandrine Lefevre-Brevart}

European Chemicals Agency

\section{Laszlo Majoros}

European Chemicals Agency

\section{Evgenia Stoyanova}

European Chemicals Agency

\section{Peter Simpson}

European Chemicals Agency

\section{Brief Communication}

Keywords: primary microplastics, regulations, environmental policy

Posted Date: February 2nd, 2021

DOI: https://doi.org/10.21203/rs.3.rs-152781/v1

License: @) (i) This work is licensed under a Creative Commons Attribution 4.0 International License. Read Full License 


\section{Abstract}

Microplastic pollution receives increasing attention of policy makers. Primary microplastics are of particular interest as they may be effectively regulated by source reduction. We identify major emission sources and sinks of primary microplastics in the EU and discuss key challenges for optimal regulation

\section{Main Text}

Microplastic pollution receives increasing attention of policy makers. Primary microplastics are of particular interest as they may be effectively regulated by source reduction. We identify major emission sources and sinks of primary microplastics in the EU and discuss key challenges for optimal regulation.

Microplastics (commonly defined as plastic particles $<5 \mathrm{~mm}$ ) make up more than $90 \%$ of all the pieces of plastic debris that pollute our oceans (1). As only $2-5 \%$ of the plastic waste generated on land ends up in the oceans (2), microplastics are a growing concern for terrestrial ecosystems as well (3). These minute particles may be ingested by and accumulate in animals and plants (4); they may facilitate microbial dispersal (5); and they persist for hundreds of years in the environment (6). For these reasons, microplastics are at the heart of the plastic pollution problem ( 7 ). In response to calls for regulatory action, the European Chemicals Agency has recently proposed a restriction under the REACH regulation [(EC) No 1907/2006] which, if implemented, would become the strictest regulation of primary microplastics in consumer, professional and industrial supply chains anywhere in the world. The proposed restriction (8) foresees bans for many existing uses in consumer and professional products that would help to significantly curb primary microplastic emissions in the EU. Drawing on the experience of preparing the restriction proposal, we identify major emission sources and sinks in the EU and discuss key challenges in regulating uses of primary microplastics.

Whilst microplastic pollution has become an everyday topic, most of the attention has focused on secondary microplastics that result from the degradation of larger plastic items. The key difference between primary and secondary microplastics is that emissions of microbeads and microcapsules that store pharmaceuticals, food additives, fragrances, fertilisers or plant protection products are essentially irremovable, whereas larger plastic fragments such as water bottles or fishing nets could, at least in principle, be removed from the environment before they further decay. Therefore, source reduction is the most effective way of fighting microplastic pollution ( 7 ).

Based on a comprehensive methodology (see Supplemental Information), we assessed the fate of microplastics within the waste treatment processes these particles are subject to after their use and disposal. Fig. 1 shows major sources and sinks of primary microplastic emissions in the EU. In 2017, the total amount of primary microplastics added to products that were placed on the EU market was estimated to be 144,500 metric tons (MT), of which 42,400 MT were emitted to the environment via wastewater, solid waste, or direct deposition to soil pathways. 16,000 MT of the identified emissions are attributable to microplastics used as infill on artificial turf sports pitches. The remaining $26,400 \mathrm{MT}$ are shared between uses in agricultural products, various household care products and cosmetics as well as paints and coatings. Medical devices and medicinal applications are minor emission sources. Accidental emissions from industrial uses of plastic pellets and powders that serve as precursors for manufactured plastic products were omitted from the analysis as such losses do not occur intentionally.

One way to contextualize these emission estimates is by means of a comparison to plastics currently produced, consumed, recycled, incinerated, landfilled and otherwise disposed of in the EU. We provide such a comparison based on information for the EU28 plus Norway and Switzerland (EU28+). In 2018, the EU28+ industry converted 51.2 million MT of plastic raw materials; in the same year, 29.1 million MT of plastic waste were collected through official schemes for recycling, incineration or landfill (9). A recent study on global plastics production (10) finds that for every 4 million MT of plastics entering the use phase, 3 million MT of plastics exit. Based on this ratio, we estimate that the total amount of plastic waste that corresponds to the 2018 consumption in the EU28+ was 38.4 million MT, of which 29.1 million MT were collected. This suggests that about 9.3 million MT of differently sized, shaped and composed plastics were disposed to the EU28+ environment in 2018. 
This quantity may be compared against the estimated emissions of primary microplastics. By weight, the 2017 emissions of primary microplastics corresponded to approximately $0.5 \%$ (lower bound: $0.1 \%$; upper bound: $1.0 \%$ ) of the total plastic waste disposed in the EU28+ without proper control. Another way to contextualise the size of pollution is to compare primary microplastic emissions in the EU to the microplastic fraction of the Great Pacific Garbage Patch (GPGP). Assuming the same composition of plastic debris as estimated for the GPGP (1), the annual primary microplastic emissions in the EU are composed of 11.5 trillion particles and correspond to a garbage patch more than six times the current size of the GPGP (see Table S4).

This particle-based comparison suggests that primary microplastic emissions warrant regulatory actions beyond those for plastic litter in general ( 7 ). We see several parallels to greenhouse gas (GHG) emissions: primary microplastics are released to the environment by many individual point sources; once emitted, it is not possible or prohibitively expensive to clean up; and their biodegradation in the environment is expected to take hundreds of years so that emissions are irreversible and contribute to an ever-increasing pollution stock. There is, however, one decisive difference. Microplastics are less mobile than GHG and therefore, at least in the short term, more likely to accumulate in the environmental compartment to which they are released (4). This implies that the free-rider problem plaguing GHG emission reduction agreements may be overcome by unilateral regulatory actions to curb emissions (11) and slow down the growth of the microplastic pollution stock in the EU.

Three issues seem particularly relevant for determining what regulatory actions are socially optimal to tackle primary microplastic emissions. The first relates to irreversibility which poses a challenge to conventional policy analysis because the long-term consequences of microplastic pollution are poorly understood and cannot be priced reliably. This leads to a situation wherein the costs of regulation cannot be directly compared against its benefits. Instead, one may turn to an abatement cost approach. The REACH restriction proposal (8) contains estimates of the sector-specific cost to substitute primary microplastics with biodegradable polymers and other materials, implying the marginal abatement cost (MAC) curve depicted in Fig. S3. In key sectors, the expected abatement cost for primary microplastics is well below $€ 1,000$ per $\mathrm{kg}$ (Table S5). Unless ways are found to reduce emissions of secondary microplastics at equal or lower cost, there is an economic rationale to abate were the abatement is least costly.

While providing a good sense of the order of costs expected from replacing primary microplastics in various industry sectors, this does not capture the social desirability of such phase-outs. Banning primary microplastic uses that are considered to be less essential for society will result in more desirable outcomes than banning them in applications where they provide beneficial functions for health and safety that are currently not achievable with alternative substances or technologies (12). From a human and environmental health perspective, medicinal and agricultural uses appear to be most relevant, and finding functional alternatives for these uses of primary microplastics should become a research priority.

Notwithstanding challenges in determining what is and is not essential for society, it may be optimal to ban certain uses of microplastics based on precautionary motives (13). The anticipation that we will learn more about the harmfulness of microplastics for both aquatic and terrestrial ecosystems in combination with the extreme persistence of microplastics in the environment reinforces the value of swift regulatory action (14). Although the consequences of microplastic pollution are not yet fully understood, there is enough evidence (15) that supports regulating the use of primary microplastics now, rather than later. An ensuing question is how fast bans and other regulatory measures should apply. Here, a balance needs to be struck between curbing primary microplastic emissions as fast as possible and avoiding disruptive regulation that may impede rather than promote the development of safe and functionally equivalent alternatives. Optimal regulatory roll-out will require sectorspecific transition periods that set binding phase-out dates which are ambitious but account for the time and costs needed to develop and implement alternatives.

\section{Declarations}

Acknowledgments: The authors thank Mark Blainey, Greta Franke, Giorgi Kvatchadze, Matti Vainio, and Peter van der Zandt for comments on and contributions to the research presented. Statements in this publication reflect the authors' professional views and opinions and should not be construed to represent any determination or policy of the European Chemicals Agency.

Page $3 / 5$ 
Funding: Authors declare no external funding.

Author contributions: Christoph M. Rheinberger: Conceptualization, methodology, investigation, writing - original draft, visualization; Pertti Elo: Formal analysis, investigation, data curation; Sanna Henrichson: Formal analysis, investigation, data curation. Anu Kapanen: Formal analysis, investigation; Sandrine Lefevre-Brevart: Formal analysis, investigation, project management; Laszlo Majoros: Formal analysis, investigation, data curation; Evgenia Stoyanova: Methodology, formal analysis, investigation, data curation; Peter Simpson: Conceptualization, supervision, writing - review and editing.

Competing interests: Authors declare no competing interests.

Data and materials availability: All publicly available data considered during the investigation can be retrieved from the official website of the European Chemicals Agency under: https://echa.europa.eu/registry-of-restriction-

intentions/-/dislist/details/0b0236e18244cd73. Data claimed confidential by stakeholders are not accessible to the public. All data, code, and materials used in the analysis of this paper are available from the authors.

\section{References}

1. Lebreton, L. et al. Evidence that the Great Pacific Garbage Patch is rapidly accumulating plastic. Rep. 8, 4666 (2018).

2. Jambeck, J. R. et al. Plastic waste inputs from land into the ocean. Science 347, 6223 (2015).

3. De Souza Machado, A. A. et al. Microplastics as an emerging threat to terrestrial ecosystems. Chang. Biol. 24, 1405 (2018).

4. Rochman, C. M. Microplastics research-from source to sink. Science 360, 6384 (2018).

5. Amaral-Zettler, L. A. et al. Ecology of the plastisphere. Rev. Microbiol. 18, 139 (2020).

6. Thompson, R. C. et al. Lost at sea: where is all the plastic? Science 304, 838 (2004).

7. Rochman, C. M. et al. Scientific evidence supports a ban on microbeads. Sci. Technol. 49, 10759 (2015).

8. European Chemicals Agency (ECHA), Background Document to the Opinion on the Annex XV Restriction Report on intentionally added microplastics (ECHA, 2020); https://echa.europa.eu/registry-of-restrictionintentions/-/dislist/details/0b0236e18244cd73.

9. PlasticsEurope, Plastics - the Facts 2019 (PlasticsEurope, 2019); https://plasticseurope.org/application/files/9715/7129/9584/FINAL_web_version_Plastics_the_facts2019_14102019.pdf.

10. Geyer, R. et al. Production, use, and fate of all plastics ever made. Adv. 3, e1700782 (2017).

11. Nordhaus, W. Climate clubs: Overcoming free-riding in international climate policy. Econ. Rev. 105, 1339 (2015).

12. Cousins, I.T. et al. The concept of essential use for determining when uses of PFASs can be phased out. Sci. Process. Impacts 21, 1803 (2019).

13. Gollier, C \& Treich, N. Decision-making under scientific uncertainty: the economics of the precautionary principle. Risk Uncertain. 27, 77 (2003).

14. Traeger, C. P. On option values in environmental and resource economics. Energ. Econ. 37, 242 (2014).

15. Bujnicki, J. et al., Environmental and health risks of microplastic pollution (European Commission, Group of Chief Scientific Advisors, Scientific Opinion 6/2019); https://doi:10.2777/65378.

\section{Figures}




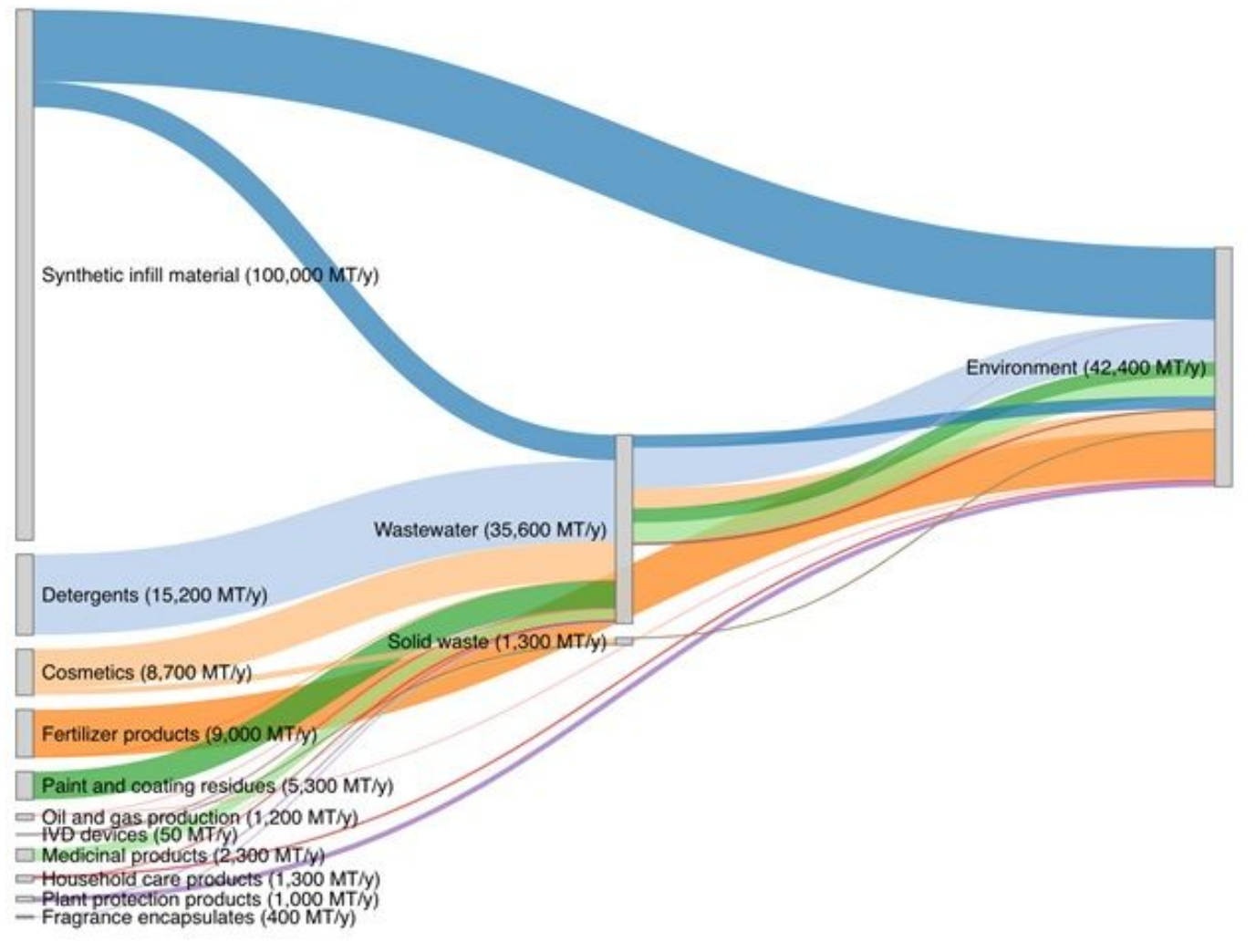

\section{Figure 1}

Sankey plot showing major sources and sinks of primary microplastic emissions in the EU. Emissions to the environment include those to both the aquatic and terrestrial compartment. Data taken from (8). More information on emission sources and sinks is provided in Tables S1-3.

\section{Supplementary Files}

This is a list of supplementary files associated with this preprint. Click to download.

- SupplementaryMaterialsPMP.docx 